\title{
La tradición centralista en América Latina*
}

Las consecuencias más obvias de los recientes intentos para reformar, modernizar o transformar los países latinoamericanos parecen ser la desilusión y la perplejidad. Estoy convencido de que ello es un resultado de la creencia errónea en que la experiencia de los países industrializados de la Europa noroccidental y los modelos interpretativos derivados de ésta pueden ser aplicados en forma precisa a los pueblos de las regiones sureñas del Nuevo Mundo. Estoy también convencido de que la proliferación de los regimenes autoritarios durante los últimos años no es una aberración de tipo moral o político sino lá manifestación de un estilo de comportamiento político; una disposición secular de la sociedad latinoamericana que permanecerá con nosotros todavía durante un tiempo, bajo diferentes formas, de las cuales la militar bien puede ser muy transitoria. La principal hipó tesis presentada en este trabajo proporciona una base para estas afirmaciones. Esta hipótesis se fundamenta en la clescripción y el análisis de los principales factores que distinguen el carácter social, económico y político de las sociedades latinoamericanas de aquel: que distingue a los países que comparten la tradición europea noroccidental. Estos factores tuvieron una influencia decisiva en la génesis y la formación de las sociedades latinoamericanas. Ellos conservan su importancia en la actualiclad y creo que continuarán siendo muy significativos en el futuro. A pesar de que aquí los enunciaré separadamente, no son separables, sino que se interpenetran e interactúan unos con otros, por lo cúal en este trabajo aparecerán entretejidos a lo largo del tratamiento histórico del tema. Cuatro de estos factores están inversamente relacionados con lo que he decidido llamar el carácter "centralista" del orden social y político de los países de América Latina: el primero es la ausencia de la experiencia feudal en la tradición latinoamericana; el segundo es la ausencia de un no

*Introducción al libro titulado, The Centralist Tradition of Latin America, de próxima publicación. 
conformismo religioso y el Iatitudinario centralismo provocado por la religión dominante; el tercero es la ausencia de algún suceso o circunstancia que a lo largo del tiempo pueda ser razonablemente considerado como una contrapartida de la revolución industrial europea; el cuarto es la ausencia de aquellos sucesos ideológicos, sociales y políticos asociados con la Revolución Francesa, que transformaron de manera tan dramática el carácter de la sociedad europea occidental durante el último siglo y medio.

Esos son factores negativos que, si bien apoyan firmemente el argumento que se presenta en este trabajo, pueden ser insuficientes para explicar las características especiales de la América Latina moderna. Por consiguiente, voy a proponer más adelante que la sociedad latinoamericana presenta características que en otras partes, notablemente en los países pertenecientes a la corriente cultural de Europa noroccidental, están asociados con las consecuencias de la Revolución Industrial, pero que aquí tienen un claro origen y orientación preindustrial. Estas consisten en una tradición burocrática y racionalizante de cuño preindustrial en la cual se funda el centralismo que ha conformado los procesos de cambio y de continuidad de esos países, y una cultura urbana preindustrial sui generis dentro de la cual se ha desarrollado un vasto sector terciario, intimamente inseparable de las instituciones y hábitos burocráticos ${ }^{1}$.

$\mathrm{El}$ argumento que se presenta en este trabajo puede también resumirse estableciendo que América Latina ha sido pasada por alto las revoluciones industrial y francesa y sus consecuencias más significativas. Las tendencias racionalizadoras y centralizadoras inherentes a sus instituciones burocráticas estaban presentes dos siglos antes de la caída de la Bastilla y han conservado su carácter preindustrial. Si la revolución industrial dio origen a un masivo proceso de cambio social,

'El historiador español José Antonio Maravall ha impregnado a aquellos que, como el lo ve, interpretan la historia española en forma negativa, destacando lo que presumiblemente no se encuentra en ello: el feudalismo, la burguesfa, el iluminismo, etc. El cree que para que un trabajo histórico sea aceptable "nunca puede ser el perfil negativo de un vacio. Lo que debe decirse es lo que está positivamente allf". También sugiere que puede ser erróneo prestar atención a estas ausencias excesivamente dramatizadas, porque ellas simplemente pueden reflejar el hecho de que Ias instancias españolas de algún fenómeno general son muy poco usuales. Existió una burguesía española, pero fue notablemente diferente de las variedades orleanistas o toscanas.

A pesar de que se admira el trabajo de este historiador, no estoy preparado para seguirlo en este punto. Creo tanto útil como razonable, por ejemplo, cerciorarse acerca de si la España medieval experimentó aquello que nosotros denomi- 
principalmente a causa de las demandas de una tecnología de trabajo intensiva, en fuerza de trabajo, en América Latina la industrialización introdujo una tecnología intensiva en capital que necesitó diferentes ajustes para operar en el nuevo medio. Si la revolución industrial puede ser justamente vinculada con los esfuerzos de una burguesía industrial que, a su vez, generó un proletariado industrial, en América Latina la industrialización no fue el resultado de las actividades de una burguesía industrial ni dio lugar a un proletariado industrial equivalentes a sus contrapartidas europeas.

Desde Marx a Weber y Talcott Persons muchos estudiosos del cambio social han convenido en que "el tipo moderno de sociedad ha emergido en un solo escenario en evolución, el de Occidente, que representa esencialmente aquella parte de Europa que recibió en herencia la mitad occidental del Imperio Romano al Norte del Mediterráneo"2. También han estado de acuerdo en que los elementos fundamentales de la moderna sociedad occidental pueden entenderse mejor como otras tantas "respuestas al problema del orden que se planteó en los comienzos del siglo xxx por el colapso del viejo régimen bajo los golpes del industrialismo y la democracia revolucionaria... dos fuerzas monumentales en su significación"3. Por cierto monumentales, porque marcaron "la transición desde la temprana fase de la modernidad occidental hacia la que cristalizó a mediados del siglo veinte"4. Aún más enfática es la afirmación de Hobsbawn de que la revolución dual "que estalló entre 1798 y $1848 \ldots$ produjo la mayor transformación en la historia humana desde los remotos tiempos en

namos "feudalismo". No estoy convencido de la afirmación de Maravall de que son más útiles las afirmaciones positivas que las negativas. Seguramente, decir que el rey sobrevivió puede ser tan útil como decir que no está muerto. También, es conocidamente difícil saber precisamente cuáles pequeñas diferencias son tan completas como para garantizar cambios mayores. Pero, esa burguesia española que Maravall concibe ¿es tan diferente como para dejar de ser una burguesía? Maravall, por supuesto, sólo se está refiriendo a la historia española, pero como la historia española emerge inevitablemente de la española, considero apropiado destacar que en este trabajo intentaré hacer un uso legitimo tanto de las afirmaciones positivas como de las negativas, y que estos usos son absolutamente sin referencias a la inquietud expresada por el distinguido historiador español. Ver José Antonio Maravall, Estado moderno y mentalidad social, Madrid 1972, I, 7-8.

${ }^{2}$ Talcott Persons, The System of Modern Societies, Englewood Cliffs, N. J. 1971, p. 1.

${ }^{3}$ R. A. Nisbet, The Sociological Tradition, London, 1972, pp. 21-22.

'Parson, The System, p. 74. 
que el hombre inventó la agricultura, la metalurgia, la escritura, la ciudad y el estado"5. Exagerado o no, me parece innecesario disentir con el espiritu de estas afirmaciones, y es en este estendido que baso mi comprensión del significado crucial que la ausencia de las revoluciones industrial y francesa ha tenido para el desarrollo histórico de las sociedades latinoamericanas. También me parece que esto enfatiza convenientemente la gran importancia de una tradición centralista que precedió la llegada de la industria por varios siglos y que constituyó el dominador común de las transformaciones y continuidades discernibles a lo largo de la historia económica, social y política de las naciones latinoamericanas.

Aqui sería legítimo esperar una cuidadosa definición del término "centralismo", que de otro modo permanecería difuso y abierto a una variedad de interpretaciones. Sin embargo, preferiría dejar que las consideraciones expuestas en este estudio nos hicieran comprender por sí mismas el significado y las limitaciones de este concepto. Al respecto, me agrada apoyarme en la sabia sentencia del profesor Gellner según la cual "sería un requerimiento absurdo restringix la interpretación sociológica a conceptos claros y distintos. Históricamente, ellos constituyen una rareza y no hay nada que a uno pueda llevarlo a negar que nociones vagas y amplias, cuyas inferencias lógicas para la conducta están mal determinadas, de hecho pueden tener un impacto poderoso y específico en el comportamiento actual"'.

Ciertamente, creo que durante los cinco últimos siglos el centralismo ha tenido un impacto muy "poderoso y específico" en el comportamiento de los latinoamericanos, y me contentaré con dejar la argumentación en este punto, sujeta tan sólo a una calificación: el "centralismo"; como se usa aquí, no debe ser confundido con el "patrimonialismo", un concepto esencialmente diferente y de alguna forma antitético al sesgo burocrático que posee el centralismo latinoamericanot. En el patrimonialismo, el ancestro, la herencia y la persona-

Eric J. Hobsbawn, The Age of Revolution: Europe from 1789-1848, London, 1962, p. 15.

- Ernest Gellnet, "Concepts and Society", en Sociological Theory and Philosopical Analysis, ed. Dorothy Evenet and Alistair Mac Intyre, London, 1970, p 116.

THa habido un buen número de buenos estudios sobre el patrimonialismo latinoamericano, entre los cuales debe mencionarse: Megali Sarfatti; Spanish Bureaucratic Patrimonialism in America, Politics of Modernization Series No 1. Berkeley, Calif, 1966; Howard Wiard, ed., Politics and Social Change in Latin America; The District Tradition, Amherst, Mass, 1974; y Riordan Roett, Brasil, Politics in a Patrimonial Society, Boston, 1972. 
lidad juegan un papel definitivo; en el centralismo, su papel es excepcional o accidental. El concepto de patrimonialismo cae dentro de la categoría weberiana de la "autoridad tradicional", mientras que el centralismo debería por cierto ser clasificado bajo la categoría de la "dominación de tipo racional" que emplea Weber. Cualesquiera sean sus limitaciones y sus excesos -y ellos no son escasos en cinco centurias colmadas de eventos- la tradición centralista burocrática ha encontrado su expresión a través del oficio antes que del hombre, satisfaciendo así la condición fundamental puesta por Marx y Weber para un moderno sistema social de base burocráticas. La victoria de La Gasca sobre Pizarro -el leal empleado público sobre el héroe militar disidente- ha sido pregonada a través de los siglos hasta nuestros tiempos, suministrando abundante evidencia para apoyar la afirmación hecha por Tocqueville de que "el aumento incesante de la prerrogativa del gobierno supremo, al llegar a ser más centralizado" conduce eventualmente a situaciones en las cuales "los mismos hombres que de tanto en tanto derriban un trono y pisotean una raza de reyes se inclinan más y más obsequiosamente frente a la más pequeña orden de un empleado". Me parece claro que el centralismo y el patrimonialismo difieran sustancialmente. Debe añadirse ahora que el fenómeno del centralismo, que tanto Weber como de Tocqueville estaban describiendo, fue un resultado $-\mathrm{y}$ ambos lo comprendieron así- de las revoluciones industrial y francesa y, por lo tanto, estaba ligado estrechamente al igualitarismo y al industrialismo; en tanto que el centralismo latinoamericano precedió a estas grandes transformaciones y retiene hasta hoy en día su carácter preindustrial y no igualitario.

Este concepto de centralismo, sin definir pero cuidadosamente circunscrito, es esencial para la comprensión de un desarróllo histórico iberoamericano que ha sobrellevado alternativamente etapas de relajación del control central seguidos por otras orientadas hacia la recentralización. Si bien este estudio no está diseñado en orden cronológico, siguiendo estas etapas, creo útil describirlas a continuación,

${ }^{8}$ Es decisivo para la naturaleza especifica de la lealtad moderna hacia un oficio que, en el tipo puro, no establezca una relación con una persona, tales como la fe del vasallo y del disclpulo en las relaciones patrimoniales de autoridad. $\mathrm{H}$. $\mathrm{H}$. Gerth y C. Wright Mills, trans. y eds., From Max Weber: Essays in Sociology, N. York, 1958, p. 199.

'Alexis de Tocqueville, Democracy in America, trans. Henry Reeve, ed. Henry Steele Commager, London, 1959, pt. 2, p. 274. 
aunque en forma sucinta, para destacar el hecho de que el centralismo no ha tenido un progreso uniforme y tranquilo, sino que ha sufrido fluctuaciones notables.

EI primer período se extiende desde la segunda mital del siglo xv, cuando los monarcas católicos iniciaron con éxito el arduo proceso de la centralización de Castilla en las Cortes de Madrigal, en 1476, hasta los últimos años del siglo xvx, cuando la revuelta catalana de 1591, el gran colapso financiero de 1596 y la muerte de Felipe II, marcaron el fin de una era y el comienzo de una prolongada decadencia asociada con la relajación del control central por parte de Ios habsburgos. El segundo periodo cubrirá aproximadamente un siglo, desdé la ascención de Felipe Im hasta la muerte del último monarca habsburgo en 1700, y la llegada de los borbones al trono español. Gualesquiera sean las causas de la decadencia experimentada por España durante el siglo xvrr, una de sus principales consecuencias fue un debilitamiento de facto de los lazos que unían la periferia imperial y burocrática con la autoridad central. La vuelta a la corriente centralista de la política castellana e imperial fue anunciada por el entronamiento del duque de Aujou, con el título de Felipe v, en el trono de España. Si bien la principal embestida de las reformas recentralizadoras de los borbones no se hizo sentir hasta la última parte del siglo, el nuevo tono administrativo y político fue aparente desde los comienzos del reinado de Felipe, aunque bajo la cobertura de una fuerte influencia francesa. Este tercer período de recentralización borbónica fue paralelo a las reformas recentralizadoras de la dictadura pombaliana en Portugal, y ambos extendieron su influencia más allá de los años ocupados por los movimientos revolucionarios de la independencia y las primeras décadas del gobierno republicano, hasta mediados del siglo xIx, cuảndo el centralismo del iluminismo ibérico fue sobrepasado por la creciente ola del liberalismo comercial y político europeo.

La "pausa liberal" que se inició a mediados del siglo xrx comenzó a derrumbarse con la gran depresión de 1929, revivió por un tiempo, durante y después de la Segunda Guerra Mundial, y en forma vacilante llegó a su fin durante la decadencia económica de fines de los sesenta y principios de los setenta. Durante la última mitad deI siglo - con las inevitables variaciones de país a país- América Latina descubrió el camino de vuelta hacia su tradicional cauce centralista. A pesar de las intenciones de los revolucionarios y los reformistas, cada nueva reconstrucción ha dado como resultado un creciente con- 
trol central, y mientras más grandes era el cataclismo revolucionario más eufórico resultaba el centralismo de la estructura institucional resultante. De allí que tres movimientos revolucionarios que son considerados generalmente como los más importantes que se han producido en la región durante este siglo -aquellos de México, Bolivia y Cuba- concluyeron en sistemas de gobierno de partido único, con todo el poder reunido en el centro. Otros intentos menos importantes para reconstruir la estructura institucional de la sociedad comparten también este estilo político centralista, y la extensión del poder central ha llegado a ser una característica a largo plazo de todo estos países, sin que influya el color político de sus gobiernos.

Está más allá de toda duda el hecho de que un proceso comparable se produjo también en otros lugares del mundo, pero en tanto que las tendencias centralizadoras inducidas por las mejoras en las comunicaciones, las técnicas administrativas y otros factores similares en naciones tales como Gran Bretaña, Suecia, Australia, Nueva Zelandia, Holanda, Ios Estados Unidos, Dinamarca, Ganadá o la República Federal Alemana, encuentran una fuerte resistencia por parte del cuerpo político y las tradicionales estructuras institucionales, la tendencia centralista en América Latina está apoyada y fortalecida precisamente por una tradición política que ha sido siempre centralista y sólo excepcionalmente se ha apartado de ese camino.

Las colonias británicas en América del Norte resultaron ser un ámbito prometedor para la realización de una de las más significativas utopías privadas de los tiempos modernos; ellas proporcionaron una tabula rasa "en la cual el puritanismo fue capaz de desarrollarse con relativa libertad sin la interposición de factores externos"10. Las Indias permitieron casi el mismo grado de libertad para la construcción sin impedimentos de una de las mayores utopías públicas de la historia. Allí el inexperto estado renacentista de la corona de Castilla fue capaz de dar existencia a una estructura política centralizada, sin el lastre de las tradiciones feudales a la oposición de las baronías periféricas. Como también lo ha expresado Maravall, la evolución de las Indias fue una incomparable proeza renacentista de inventiva:

${ }^{10}$ Robert Ashton, "Puritanism and Progress", EHR, n.s. (abril, 1965), 582. No se debe olvidar que hubo un propósito en esa aventura. Como ha explicado Johnson, "El nacimiento de la América protestante fue un acto deliberado y consciente del perfeccionismo Iglesia-Estado". Paul Johnson, A History of Christianity, London, 1976, p. 421. 
América fue inventada por la España del siglo xvr11. Las Indias fueron creadas desde la metrópolis como una estructura centralizada por las mentes de políticos que contemplaban el Renacimiento desde Madrid, la capital imperial de una nación llena de confianza después de grandes victorias militares, y regida por un grupo burocrático cuidadosamente diseñado para prevenir cualquier intrusión en el poder central. Castilla, envejecida y acrisolada por siglos de luchas, en el tiempo de los grandes descubrimientos habia desarrollado una forma eficiente de gobierno centralizado, una estructura burocrática razonablemente bien organizada, una relación estable entre la Iglesia y el Estado, y un sistema de leyes suficientemente desarrollado y complejo para ser impuesto integramente a un pueblo conquistado. Fue sobre estos fundamentos civiles y burocráticos en donde la corona de Castilla erigió su edificio imperial; ésta es la causa por la cual muy pronto después de la invasión militar de las Indias, "Ios conquistadores, aventureros y cruzados cedieron paso rápidamente a administradores, abogados y jueces"12.

La consolidación e institucionalización del control imperial fue acompañada por la emergencia de un estilo político centralista, cívico, burocrático y legalista, del cual ni las Indias imperiales primero ni las repúblicas independientes de América Latina más tarde se han apartado jamás con gran convicción o éxito. Por lo demás cuando se dieron estas desviaciones, ellas no modificaron sustancialmente el edificio institucional, preexistente sino que dieron lugar a una simple relajación de facto de la autoridad centralizada. W. B. Yeats esbozó el extremo de la desilusión y la anarquía en su celebrado Things fall apart; the centre cannot hold ("Las cosas se desintegran; el centro no puede sostenerlas"). A esto, se puede replicar que en la tradición histórica latinoamericana el centro deja de ser un sostén muy rara. vez, e incluso cuando aparentemente sucumbe, pronto revive, tal vez revigorizado.

Durante los tres siglos de dominio ibérico sobre América Latina, las principales defecciones respecto al centralismo sucedieron por

Maravall, Estado moderno, 1, 38-39. O, como Raymundo Faoro ha expresado refiriéndose principalmente a la América portuguesa, se hizo posible en esa época que los príncipes y sus asesores "organizaran un Estado como si fuera una obra de arte, un acto de creación consciente y calculado" (traducción del autor). Raymundo Faoro, Os donos do poder, formaçao do patronato politico brasileiro, 3a ed. rev. Porto Alegre, 1976, x, 10.

${ }^{12}$ J. H. Harry, The Spanish Theory of Empire in the Sixteenth Century, Cambridge, 1940, p. 1. 
negligencia: La declinación de España en el siglo xvxr se reflejó en Ia indiferencia hacia las Indias o, lo que es peor, en la incapacidad para cumplir las responsabilidades inxperiales del gobierno. Desde la Independencia, la "pausa liberal" marca la desviación más impor. tante de la tradición centralista, y esto fue principalmente el resultado de una aparente ola nacionalista que intentó descartar todo lo español y reemplazarlo por la cultura más atractiva que florecía en Francia y Gran Bretaña. El concepto de un fuerte gobierno centralista y autoritario fue identificado correctamente con la tradición colonial, y rechazado en favor de la dispersión del efectivo poder económico y político, contenido en los credos liberales y radicales contemporáneos. La intelectualidad y los intereses comerciales, agrícolas y mineros dominantes coincidieron en su ferviente y sincero apoyo a las ideologías que estaban a la vanguardia de la civilización; su defensa entusiasta fue posibilitada por el auge de las exportaciones de productos primarios, que dieron paso a una prosperidad generalizada, de la que disfrutaron principalmente aquellos que estaban situados en los grupos superiores de la sociedad.

La Gran Depresión de 1929 marcó el comienzo del fin de esa afluencia fácil basada en las exportaciones de bienes primarios, pero la inclinación a la dependencia no se desvaneció de la noche a la mañana. La perplejidad, la confusión y la desilusión de las últimas décadas tienen en su raíz la paradoja esencial de un vasto conglomerado social centralista, muchos de cuyos líderes intelectuales y políticos no se han resignado a ser lo que son, sino que persisten porfiadamente en pretender en que ellos todavía son capaces de hacer que sus pueblos lleguen a ser aceptables imitaciones de los europeos, sean estos liberales británicos, radicales franceses, comunistas rusos, demócratacristianos italianos o cualquier otra variedad en boga.

Hace pocos años, Sir Isaiah Berlin, en su magnífico ensayo titulado The Fedgehog and the Fox, utiliza un oscuro fragmento de Arquiloco que dice "El zorro sabe muchas cosas pero el puercoespín sabe algo realmente importante". Sir Isaiah, advirtiendo que posiblemente todo lo que el griego quiso hacer notar fue que el zorro, a pesar de toda su astucia, es derrotado por la única defensa de que dispone el puercoespín cuando se encierra detrás de su escudo de púa, sugiere, sin embargo, que estas palabras, tomadas figurativamente, pueden conducir a otro significado más rico, y marca así una de las más profundas diferencias que dividen a los escritores y a los pensadores, o a los seres humanos en general. "Porque existe un gran abismo, por un lado, 
entre aquellos que relacionan todo con una única visión central, con un sistema más o menos coherente o articulado en cuyos términos ellos comprenden, piensan y sienten todas las cosas - un principio organizativo único y universal sólo en función del cual todo lo que ellos son y proclaman tiene significado- y, por el otro lado, aquellos que persiguen muchos fines, a menudo sin relación entre sí, e incluso hasta contradictorios". De acuerdo con Berlin, la primera clase de personas llevará vidas centrípetas y la segunda, centrífugas. "El primer tipo de personalidad corresponde a los puercoespines, el segundo a los zorros". Continúa sugeriendo que Dante, Platón, Pascal, Lucrecio, Hegel y Proust son como los puercoespines en tanto que Heródoto, Aristóteles, Erasmo, Goethe, Pushikin y Joice son como los zorros. Como él mismo señala ,no hay duda de que esta metáfora representa una simplificación, una dicotomía que al ser examinada se vuelve "artificial, escolástica y, en último término, absurda. Pero si bien no constituye una ayuda para una crítica seria, tampoco debe ser rechazada como meramente superficial o frivola; como todas las distinciones que encierran algún grado de verdad, ofrece un punto de vista desde el cual mirar y comparar, un punto de partida para una genuina investigación"13.

Es en este aspecto en el que acepto gustoso la dicotomía de Sir Isaiah. Si los escritores pueden ser clasificados como puercoespines y zorros ¿por qué no las naciones? Tal vez, con la interesante diferencia de que mientras los seres humanos no son ni lo uno ni lo otro a través de sus breves vidas productivas, las naciones pueden cambiar a través del tiempo, y el puercoespín romano evolucionar en un zorro italiano, o el zorro alemán en un puercoespín contemporáneo. Nuevamente, sin insistir demasiado en este punto, sugeriría que América Latina es un puercoespín que desde mediados del siglo xIX ha estado tratando desesperadamente de convertirse en zorro, con insignificantes resultados. La ávida imitación de la Europa Occidental, semejante a un zorro, no fue suficiente para alcanzar esta transformación durante los prósperos años de fines del siglo xIx y principios del xx. Desde la Gran Depresión de 1929 y la declinación relativa de las democracias liberales, las características del puercoespín que presenta el centralismo latinoamericano se han afirmado, ayudadas sin duda por una tendencia universal en la misma dirección. A veces, paradojalmente,

\footnotetext{
${ }^{13}$ Isaiah Berlin, The Hedgehog and the Fox, and Essay on Tolstoy's Diew of History, London, 1953, pp. 1-2.
} 
este centralismo se entroniza en nombre del liberalismo, como ha sucedido a menudo con regímenes militares deseosos de impresionar a los inversores extranjeros, pero esto no debe oscurecer el hecho de que en tales casos las políticas de liberalización económica, e incluso aquellas que pretendidamente tienden a la decentralización política, son instituidas por decretos del ejecutivo $y$ administradas bajo un severo control centralizado.

Gon el riesgo de parecer innecesariamente dilatorio, creo que es necesario explicar que si bien pocas generalizaciones acerca de América Latina son capaces de soportar un riguroso escrutinio, si es que alguna lo es, en el curso de este estudio hará un uso bastante libre de este instrumento conceptual. Las diferencias entre Hondura ry Argentina, o Haití y Chile, son tan grandes, como, por ejemplo, entre Noruega y Hungría, o Liberia y Tanzania. Más aún, está muy claro para los estudiosos serios de la historia contemporánea de América Latina que cada nación demanda un estudio separado y cuidadosamente detallado. A pesar de toda su rigurosidad decimonónica, la historiografía latinoamericana es particularmente poco impresionante cuando se ocupa crítica e imaginativamente del pasado más reciente, y para cualquier persona que intente comprender los fenómenos políticos y económicos contemporáneos resulta obligatorio penetrar profundamente en los antecedentes de tales procesos.

Esto ha sido demostrado en forma convincente por el magistral estudio de Hugh Thomas sobre la revolución cubana. Después que había planeado comenzar con el golpe de estado de Fulgencio Batista en 1952, decidió que una fecha tan reciente dejaría mucho afuera. Por lo tanto, tomó el año 1899, cuando España abandonó la isla a los Estados Unidos, lo cual también resultó insatisfactorio, como surge. de sus propias palabras.

"Este enfoque también omitía el absorbente asunto de la escla. vitud y la forma en que ella afectó decisivamente el carácter de Guba, sin hablar de la edad de oro del azúcar cubano en el siglo xux, y así, después de preguntarme si realmente existiría un punto de partida para el libro que había concebido (fuera del viaje de Colón a Cuba en 1492), finalmente elegía 1762, el año de la primera captura anglosajona de La Habana".

"Más tarde, en Cuba, me pareció que esta decisión había sido correcta, puesto que mucho de lo que parece oscuro en la actual 
escena cubana parece más comprensible colocada frente a las experiencias de las cuatro o cinco generaciones anteriores" 14 .

La necesidad de historias nacionales bien detalladas y documentadas no excluye, por supuesto, la validez de estudios más amplios, y éstos deben incluir generalizaciones, las cuales podrían ser más aceptables si estuviesen precedidas de numerosas calificaciones, pero eso sería engorroso y no necesariamente útil. En todo caso, a pesar de las limitaciones que presentan las generalizaciones usadas en este contexto, ellas son tal vez menos vulnerables de lo que se pudiera suponer, puesto que se refieren a un grupo de naciones que surgen de una raza ibérica común y comparten básicamente las mismas tradiciones históricas y culturales, la misma religión y -considerando el íntimo lazo que existe entre los idiomas español y portuguésusan el mismo vehículo lingüístico para comunicarse unos con otros. Mucho puede decirse de las diferencias entre esas naciones, pero ello no debiera oscurecer el hecho de que tienen mucho en común, que es de importancia definitiva para la construcción de su presente y de su futuro. Como indicó Marx si bien el hombre hace su propia historia, no la hace con su propia tela: "No la hace a partir de las condiciones que él escogería sino de las que se encuentran disponibles. Las tradiciones de las generaciones pasadas pesan (como una pesadilla) en el cerebro de los vivos"15. En América Latina, además de un lenguaje y una religión comunes, las tradiciones más significativas que pesan en las decisiones de los vivos incluyen también una disposición centralista que ha conferido una forma y textura muy precisos a la tela con la cual presumiblemente se hace la historia.

16 Fugh Thomas, Cuba, or the Pursuit of Freedom, London, 1971, pp. xxI-xxu.

WKarl Marx, "Der achtzchute Brumaire des Luis Napoleon", en Karl Marx Friedrien Engels Werke, Berlin, I960, vir, 115. 